\title{
Article \\ Asian Hornet, Vespa velutina Lepeletier 1836 (Hym.: Vespidae), Venom Obtention Based on an Electric Stimulation Protocol
}

\author{
Xesús Feás ${ }^{1,2, *(\mathbb{D})}$, Carmen Vidal ${ }^{3,4}\left(\mathbb{D}\right.$, M. Pilar Vázquez-Tato ${ }^{5}$ (D) and Julio A. Seijas $^{5, *(\mathbb{D})}$ \\ 1 Academy of Veterinary Sciences of Galicia, Edificio EGAP, Rúa Madrid, No. 2-4, \\ 15707 Santiago de Compostela, (A Coruña), Spain \\ 2 Fundación Instituto de Investigación Sanitaria de Santiago de Compostela (IDIS), Hospital Clínico, Edificio D, \\ $1^{a}$ Planta, Travesía da Choupana S/N, 15706 Santiago de Compostela, (A Coruña), Spain \\ 3 Servizo de Alergoloxía, Área Sanitaria de Santiago de Compostela e Barbanza, Hospital de Conxo, \\ Rúa de Ramón Baltar S/N, 15706 Santiago de Compostela, (A Coruña), Spain; carmen.vidal.pan@sergas.es \\ 4 Área de Medicina, Departamento de Psiquiatría, Radioloxía, Saúde Pública, Enfermaría e Medicina, Facultade \\ de Medicina e Odontoloxía, Rúa San Francisco S/N, 15782 Santiago de Compostela, (A Coruña), Spain \\ 5 Departamento de Química Orgánica, Facultad de Ciencias, Universidad de Santiago de Compostela, \\ Alfonso X el Sabio, 27002 Lugo, Spain; pilar.vazquez.tato@usc.es \\ * Correspondence: xesusfeas@gmail.com (X.F.); julioa.seijas@usc.es (J.A.S.)
}

check for

updates

Citation: Feás, X.; Vidal, C.;

Vázquez-Tato, M.P.; Seijas, J.A. Asian Hornet, Vespa velutina Lepeletier 1836 (Hym.: Vespidae), Venom Obtention Based on an Electric Stimulation

Protocol. Molecules 2022, 27, 138.

https: / /doi.org/10.3390/

molecules27010138

Academic Editors: Francisco J. Barba and Carla Boga

Received: 17 November 2021

Accepted: 24 December 2021

Published: 27 December 2021

Publisher's Note: MDPI stays neutral with regard to jurisdictional claims in published maps and institutional affiliations.

Copyright: (C) 2021 by the authors. Licensee MDPI, Basel, Switzerland. This article is an open access article distributed under the terms and conditions of the Creative Commons Attribution (CC BY) license (https:// creativecommons.org/licenses/by/ $4.0 /)$.

\begin{abstract}
The yellow-legged Asian hornet (Vespa velutina Lepeletier 1836 (Hymenoptera: Vespidae)) is naturally distributed in China, Southeast Asia, and India; however, recently it has been detected outside of its native area, confirmed as being established in South Korea, Europe, and Japan. Health risks and deaths caused by the invasive Vespa velutina stings have become a public health concern, being the most common cause of anaphylaxis due to hymenopterans in some European regions. This in turn has led to increased demand from medical practitioners and researchers for Vespa velutina venom for diagnostic and therapeutic purposes. In this study, a straightforward, quick, and inexpensive method for obtaining Vespa velutina venom by electric stimulation is described. The venom extracts were analyzed by nuclear magnetic resonance spectroscopy $\left({ }^{1} \mathrm{H}-\mathrm{NMR}\right)$. The availability of Vespa velutina venom will lead to improved diagnostic and therapeutic methods, mainly by venom immunotherapy (VIT), in patients allergic to this invasive species.
\end{abstract}

Keywords: Asian hornet; Vespa velutina; venom; electrical; stimulation; allergy; stings; invasive species

\section{Introduction}

Invasive alien species (IAS) are plants, animals, pathogens, and other organisms that are introduced and/or spread outside of their natural geographic range and which may cause severe ecological, economic, and social impacts on the invaded environments. The European Union experiences annual damages worth $€ 12$ billion as a result of IAS effects on human health, damaged infrastructure, and agricultural losses [1]. Recently it was estimated that IAS have cost North America $\$ 2$ billion per year in the early 1960 s to over $\$ 26$ billion per year since 2010 [2] and that the economic cost of IAS has been $\$ 1.288$ trillion over the past 50 years [3]. Over 100 examples of IAS that affect human health, sometimes with devastating effects on our livelihood, have been described and documented around the world [4].

Several IAS insect species have migrated in the last decade to Galicia, located on the north-western end of the Iberian Peninsula, and successfully colonized and spread, resulting in a broad range of consequences to recipient ecosystems and, thereby, human society [5]. Of these IAS, the yellow-legged Asian hornet (Vespa velutina Lepeletier 1836 (Hymenoptera: Vespidae)) was detected in Galicia in 2012.

Vespa velutina is naturally distributed in Southeast Asia, India, and China. It was first detected outside of its native habitat in South Korea in 2003 [6], in southwestern France in 2004 [7], on islands of Japan in 2012 [8], and on the Japanese western mainland in 2015 [9]. 
It was soon recognized as a pan-European threat after being detected in the province of Navarra, northern Spain (2010); in the north-western province of Minho in Portugal (2011); Belgium (2011); Italy (2012); Germany (2014); the Netherlands (2018); Majorca in the Balearic Islands (2015); and England and the Channel Islands (2016) [5].

The species has become a major concern to apiculture and industries relying on pollination, given that the diet of these hornet colonies is predominantly based on honey bees and other insects. In Galicia, the annual cost of lost production is estimated at more than 4.5 million euros. The Vespa velutina could be responsible for the loss of $65 \%$ of the bee colonies in infested areas [10].

Vespa velutina is not only a problem for beekeepers and their industrious flying insects, since other agricultural sectors such as fruit producers and viticulturists are also impacted. Despite this, the medical-veterinary potential of Vespa velutina should also be outlined. In the Aculeates, the defining feature is that the egg-laying ovipositor is modified to form a sting. Hymenopteran insects are not predisposed to assault and sting humans, however, social hornets, wasps, and bees have a large defensive response to any risk to the colony. The evolution of the venom system shows to have further developed to cause pain and increase the immune response in humans and different vertebrate predators [11]. Due to its habits, abundance, and wider distribution, the risk that the IAS Vespa velutina represents for human health is incomparable with other native species of hymenoptera [12,13].

Currently, in invaded areas such as Spain and South Korea, there is an increase in the number and severity of reactions in patients exposed to invasive species Vespa velutina venom. Clinical data confirm anaphylaxis to Vespa velutina to be a significant emerging problem. Anaphylaxis to Vespa velutina has increased exponentially from the first case in 2015 in our area, where it represents the most common form of Hymenoptera anaphylaxis today. More than three-quarters of incoming patients thatreported Hymenoptera anaphylaxis between December 2017 and June 2019 identified Vespa velutina as the insect responsible for the reaction. The number of incident cases of anaphylaxis caused by other Hymenoptera (Vespula species and Apis mellifera) remained stable in those years [14]. In the University Hospital in Santiago de Compostela, Spain, covering an area of 500,000 people, a total of 292 patients were receiving venom allergen immunotherapy in 2020. In South Korea, from 2010 to 2014, there were 483,233 calls requesting the removal of wasp nests and the stings of Hymenopterans caused 78,860 injuries and 49 deaths, with Polistes rothneyi koreanus Vecht and Vespa velutina being the most prevalent sources. The total medical costs associated with the stings of hornets and wasps over a 5-year period were approximately 3.2 million dollars [15]. In Galicia, the number of calls received by the emergency services "112 Galicia" related to "incidents" with the Vespa velutina totalled 42,901 in a period of 3 years (2015-2017) [5]. Two colonies of the Vespa velutina in Galicia were detected in 2012, 17 in 2013, 769 in 2014, 5022 in 2015, and 10,642 in 2016; in 2019, around 25,000 colonies were destroyed, settling widely in urban spaces [12].

The medical community is requesting Vespa velutina venom extracts to aid diagnosis and treat allergy and/or anaphylaxis through immunotherapy $[16,17]$. Venom immunotherapy is the standard of care for people with severe reactions and has been shown to reduce the risk of future anaphylactic events and risk of death [18]. The availability of locally appropriate venom extracts must be ensured in order to diagnose and treat hymenopteran venom allergies through immunotherapy [19]. The key motivation behind the present research was to obtain extracts of venom from the invasive species Vespa velutina. It therefore has a very important practical application at the clinical level and could ultimately improve the lives of those highly reactive to the sting of the invasive species Vespa velutina and cannot "yet" receive immunotherapy due the lack of readily available and reliable sources of venom extracts. 


\section{Results and Discussion}

Detailed information with all aspects required for finding, collecting, and properly handling Vespa velutina specimens, as well as apparatus and methods used for venom extraction, are described in the present work.

\subsection{Collection and Identification of the Insects}

At first glance, the sampling of the Vespa velutina specimens seems trivial. Vespa velutina is almost ubiquitous in the invaded areas. However, sampling insects requires knowledge of their biology, preferred habitats, and activity patterns. Apiaries are hot spots for the collection of Vespa velutina, as they are concentrated, abundant, and easy to capture [20]. Vespa velutina are notorious honey bee hawkers. They fly continuously and hover around the beehive entrance at a distance of 10-40 cm (Figure 1), and hunt in flight by intercepting arriving or departing honey bees to the beehive, grabbing the foragers with their outstretched legs.

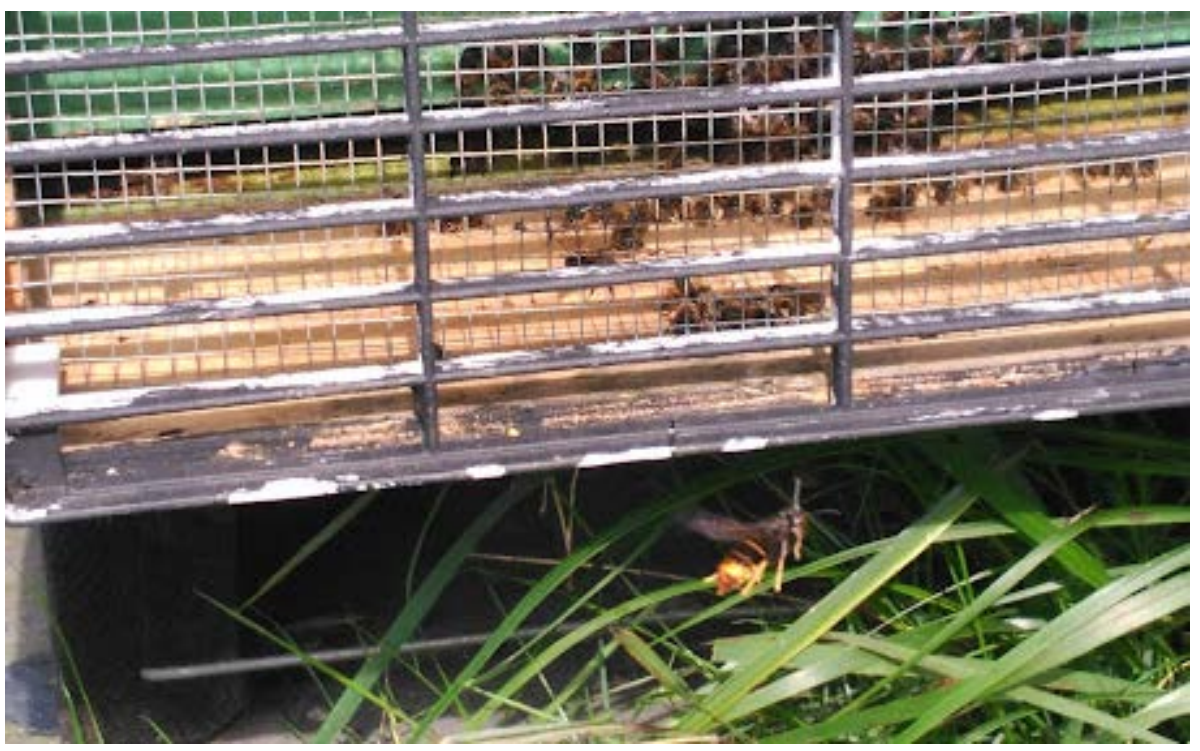

Figure 1. A female Vespa velutina specimen in static flight in front of the beehive's entry at the apiary, located in San Pedro de Viveiro at the province of Lugo (Galicia, Spain).

The target insect is not easily confused with any other hymenopteran species of hornet, bees, and wasps normally present at the apiaries in different areas of Europe, such as the European hornet, Vespa crabro Linnaeus, 1758; Vespa orientalis Linnaeus, 1771; Bombus spp; Vespula spp; and/or Polistes spp. The Vespa velutina can be clearly differentiated because of its unique dark colour pattern, which is mostly black. Moreover, the Vespa velutina has the fourth abdominal segment almost entirely orange-yellow; is smaller than the native European hornet, Vespa crabro Linnaeus, 1758; and possesses yellow-tipped legs (Figure 1).

The availability of arthropod venom still remains as the main barrier in arthropod toxinology. The difficulties in obtaining sufficient amounts of arthropod venom are either due to scarcity of the given venomous animal and/or the difficulties in the collection of its venom [21]. The distinctive Vespa velutina honey bee-capture behavior allows the pinpointing of apiaries as an ideal place, to catch enough live specimens for posterior venom extraction. The Vespa velutina colonies are typically at their maximal size in late summer and/or early autumn, with thousands of individuals in their nests, increasing their presence at the apiaries. Vespa velutina specimens were collected in an apiary in Viveiro, around $20 \mathrm{~km}$ away from the one of the first two original entry points of Vespa velutina detected in Galicia in October 2012 (GPS, UTM; X: 632451, Y: 4834800) [5].

Based on our field experiences and long term observations and research of the Vespa velutina, we carried out an effective sampling and easy transferral of the Vespa velutina 
from the apiary with a net to the venom extraction box (Figure $2 \mathrm{a}-\mathrm{c}$ ). Since Vespa velutina specimens are abundant in static flight in front of the beehives at the apiary, a fast horizontal swing of the net allows for the effective capture of this insect. Efficient use of a net to capture the Vespa velutina is gained only with experience. With a little practice, this becomes quite simple to perform. Because the hornets display positive phototropism, they facilitated their transfer from the net to the venom extraction box by moving through the black tube towards the light.

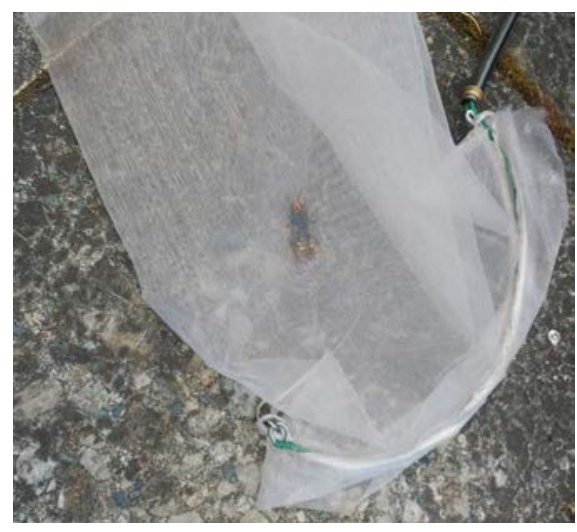

(a)

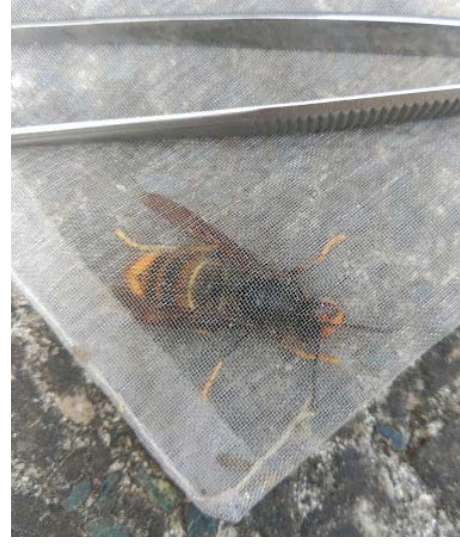

(b)

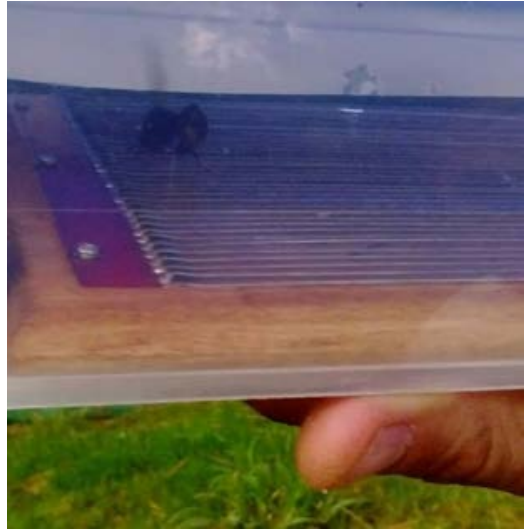

(c)

Figure 2. A captured female Vespa velutina specimen by aril netting: (a) Walking up into the net bag; (b) Trapped in a fold of the tip net bag; (c) Inside the designed chamber for venom extraction.

\subsection{Electric Stimulation}

The Vespa velutina venom extraction chamber is lightweight $(1.3 \mathrm{~kg})$ and mobile, so it can be used out in the field. The electrical venom collection device is an all-in-one solid, smart compact, working with automatic tuning where a microprocessor monitors and adjusts pulses, based on humidity, number of insects, how long the device has been running, the battery level, and the venom collector's overall condition. The access to the on/off button allows users to operate the device safely. Every $50 \mathrm{~s}$, the device pauses for $10 \mathrm{~s}$. After 40 min of work time, the device turns off automatically. That was the maximum time for Vespa velutina venom collection in one session, for a total of 10 individuals.

A close visual inspection of the electrical venom collection device (Figure 3a,b) allows us to observe liquid globules on the over the glass plate (Figure 3c), where globules crystallize or dehydrate quickly with exposure to the air. Once transported to the lab, in less than 2 hours, no liquid is observed on the plate, although an inspection under ultraviolet light does reveal small spots on the glass (Figure 4a). The dried venom was removed from the glass plates carefully with a razor (Figure $4 \mathrm{~b}$ ).

At a lab-scale level, there are well tested and widely accepted techniques for obtaining venom from several hymenopterans, such as: (i) Polybia paulista Ihering, 1896 [22]; Apis mellifera carnica Linnaeus, 1758 [23]; and Vespa affinis Linnaeus, 1764 [24]; and (ii) Vespula maculifrons Buysson, 1905; Vespula germanica Fabricius, 1793; Vespula vulgaris Linnaeus, 1758 [25]; Polistes annularis Linnaeus, 1763; Polistes carolina Linnaeus, 1767; Polistes exclamans Viereck, 1906; Polistes fuscatus Fabricius, 1793; Polistes instabilis Saussure, 1853; and Vespula germanica Fabricius, 1793 [26]; Dolichovespula maculata Linnaeus, 1763; Polistes annularis Linnaeus, 1763; and Vespula vulgaris Linnaeus, 1758 [27].

They are based on dead, frozen insects, where the whole sting apparatus needs to be dissected, using microsurgical forceps, and the obtained venom sacs are basically: (i) manually extracted from the separated venom sacs, i.e., by gentle squeezing, or (ii) homogenized and/or just pooled to collect the liquid fraction by centrifugation. 


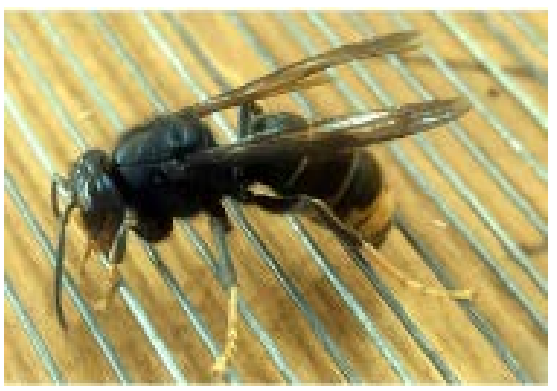

(a)

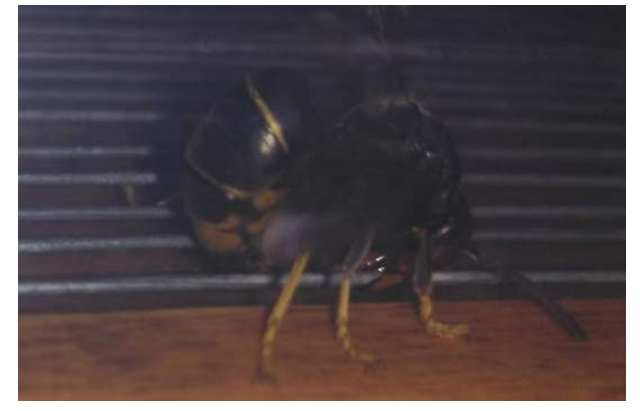

(b)

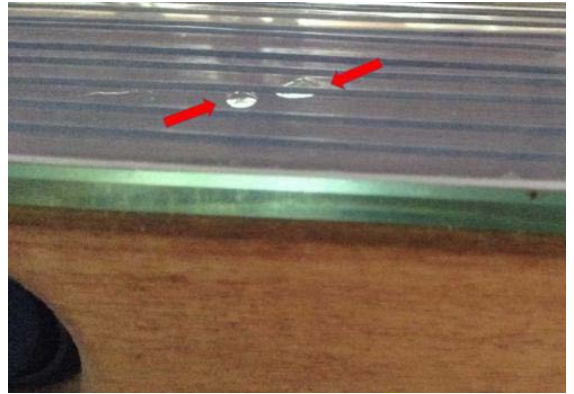

(c)

Figure 3. A female Vespa velutina specimen in the milking grid: (a) Resting, venom collection device off; (b) Bending the tip of their abdomen downward and stinging after receiving an electrical shock, venom collection device on; (c) Deposited liquid globules of venom over the glass plate (red arrows).

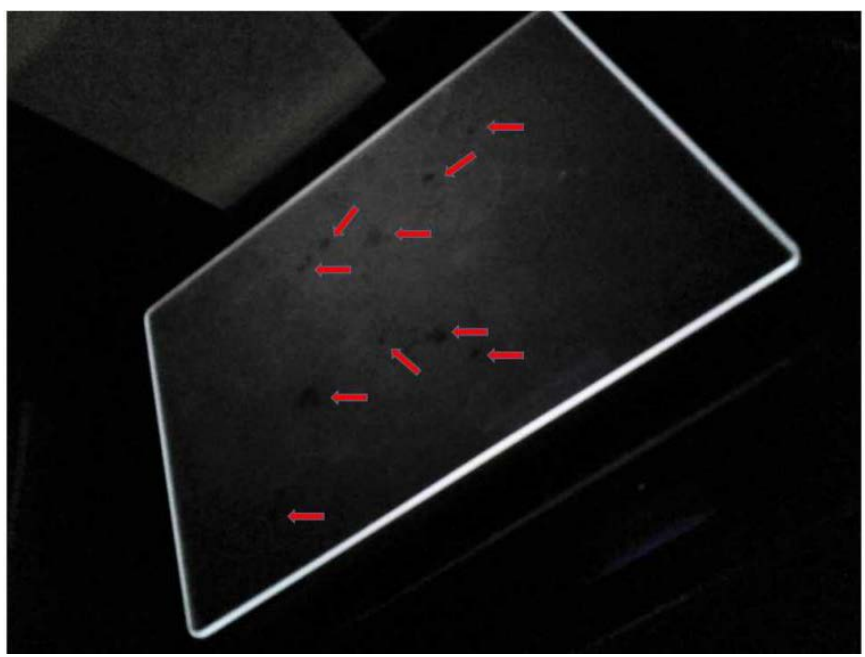

(a)

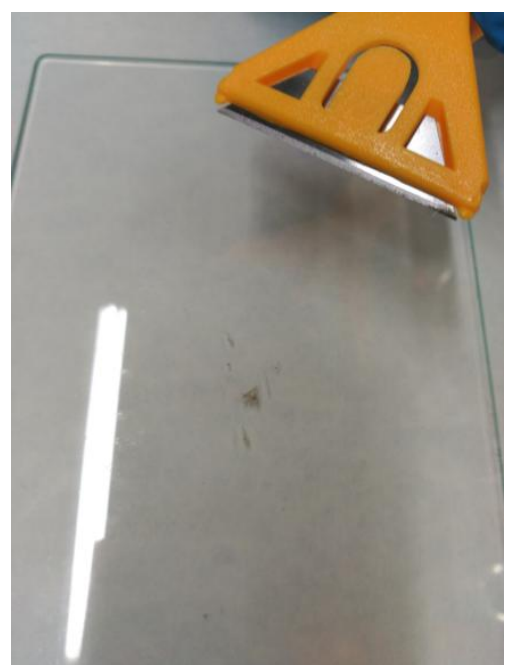

(b)

Figure 4. At the laboratory, the removed glass plate from the venom collector device after Vespa velutina electric stimulation (a) under UV light, showing venom-dried spots (red arrows); (b) scrape of the venom.

The above existing venom extraction protocols [22-27] are followed to obtain actual Vespa velutina venom [28-31]. The venom reservoir of the Vespa velutina is about $1 \mathrm{~mm}$ in length, white and transparent, [28,29] and the microdissection of the venom reservoir, usually by the precise manipulation of specialized needles, requires a high degree of operator skills. This makes the manual extraction of venom a tedious, laborious, and time-consuming task.

Li et al. demonstrated that honey bee venom extracted manually is different from venom extracted using electrical stimulation, and these differences may be important in their use as pharmacological agents [32]. The venom extracted manually is contaminated by non-toxin proteins that may leak from the gland tissue that is cut/disrupted during venom collection. Data reported by Li et al. showed that the toxin component in the venom of manual collection has significantly lower content than venom from electrical stimulation. The three newly identified phosphorylated honey bee venom proteins in the venom extracted through the use of electrical stimulation may elicit a different immune response through the specific recognition of antigenic determinants [32]. A comparison of venom from three vespid species (Vespula maculifrons, Vespula maculata and Vespula arenaria) collected by venom sac extraction and electrostimulation showed potent allergens, the last one having the potential advantage of being free of contaminating tissue protein [33]. There 
is a scope for future research, using modern technology, to assess the potential differences between a vespid venom, in this case, venom from Vespa velutina, obtained by both methods: manual extraction and by electrical stimulation. Venom from gland extracts may possess components derived from the gland's epithelium, muscular layer, nerves, etc. Furthermore, it was suggested that foreign enzymes included in the gland extracts may affect the active components of the venom [21].

A variety of stimulation techniques have evolved and are available for the collection of venom from individual Hymenoptera as well as simultaneously from a large numbers of insects [34-38]. Since the first venom extraction carried out in 2017, we continued to develop the technique, adapting the venom extraction box, on account of a specific behaviour of a whole colony in their nest, and were able to obtain venom extracts by electro stimulation of several hundreds of individual hornets, obtained directly from a captive nest (Figure 5). The above allows the collection of more venom over a short time (Suplementary video 1). However, to use a live Vespa velutina nest for milking the venom of their inhabitants is a high risk activity, needing skill that requires specialist training, specific working places, and more resources and infrastructure.

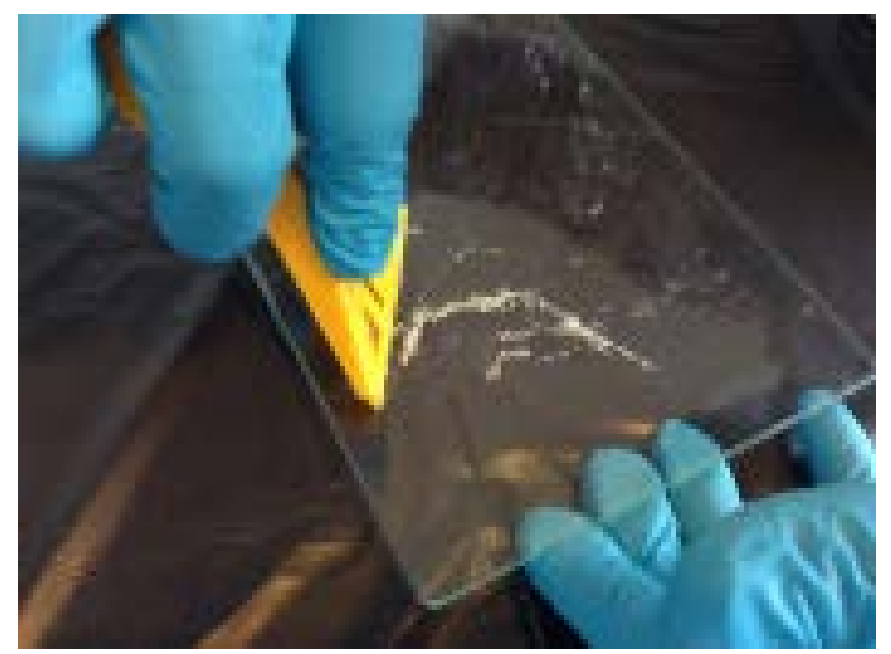

Figure 5. Scrape of the Vespa velutina venom obtained from a colony of 960 individuals from a captive nest last November 2020.

Targeted netting to capture the insect can provide enough samples of Vespa velutina specimens for venom collection by electrical stimulation. However, in the specific case of social wasps, there is a long tradition of harvesting wild nests to eat larvae and pupae, as well as the use of nests in medicine recipes. Moreover, collectors have also developed practices that can be understood to some extent as incipient vespiculture [39]. Although rigorous testing is required as current Vespa hornet rearing efforts are undeveloped, research indicates the prospect of a functional year-round Vespa hornet rearing process being developed. The current biological, ecological, medicinal, and culinary motivations justify the development of true hornet vespiculture [40]. We expect that the method developed here for venom extraction of the Vespa velutina will prove satisfactory for collecting venom from other species of venomous arthropods and/or stinging insects, as well as reared colonies of bumblebees, wasps, and hornets. Breeding of such target insects would reduce the necessity of wild harvesting.

A prerequisite to studying the nature of the venoms is the development of methods for their collection. The collection of venom should no longer be a limiting factor as this work details a successful method to allow for the easy collection of venom. Integrating transcriptomic and proteomic analyses should provide a better understanding of: the (i) venom composition of venomous hymenoptera in particular; and (ii) mammalian immune system responses to those stinging insects. It is hoped that this will assist in any future applications 
of venoms into diverse biomedicine and the possible discovery and development of new pharmacological agents and other related research areas [31,41-45].

\section{3. ${ }^{1} H-N M R$ Vespa Velutina Venom Analysis}

The collected venom was dissolved in methanol- $\mathrm{d}_{4}\left(\mathrm{CD}_{3} \mathrm{OD}\right)$ and analyzed by ${ }^{1} \mathrm{H}-$ NMR (500 MHz). In the proton spectrum (Figure 6), three regions (A, B, and C) can be observed in the enlargements (Figures 7-9). Expanded region A ( $\delta=6.5-8.7 \mathrm{ppm})$ shows the signals of aromatic hydrogens present in tryptophan, phenylalanine, tyrosine, and histidine.

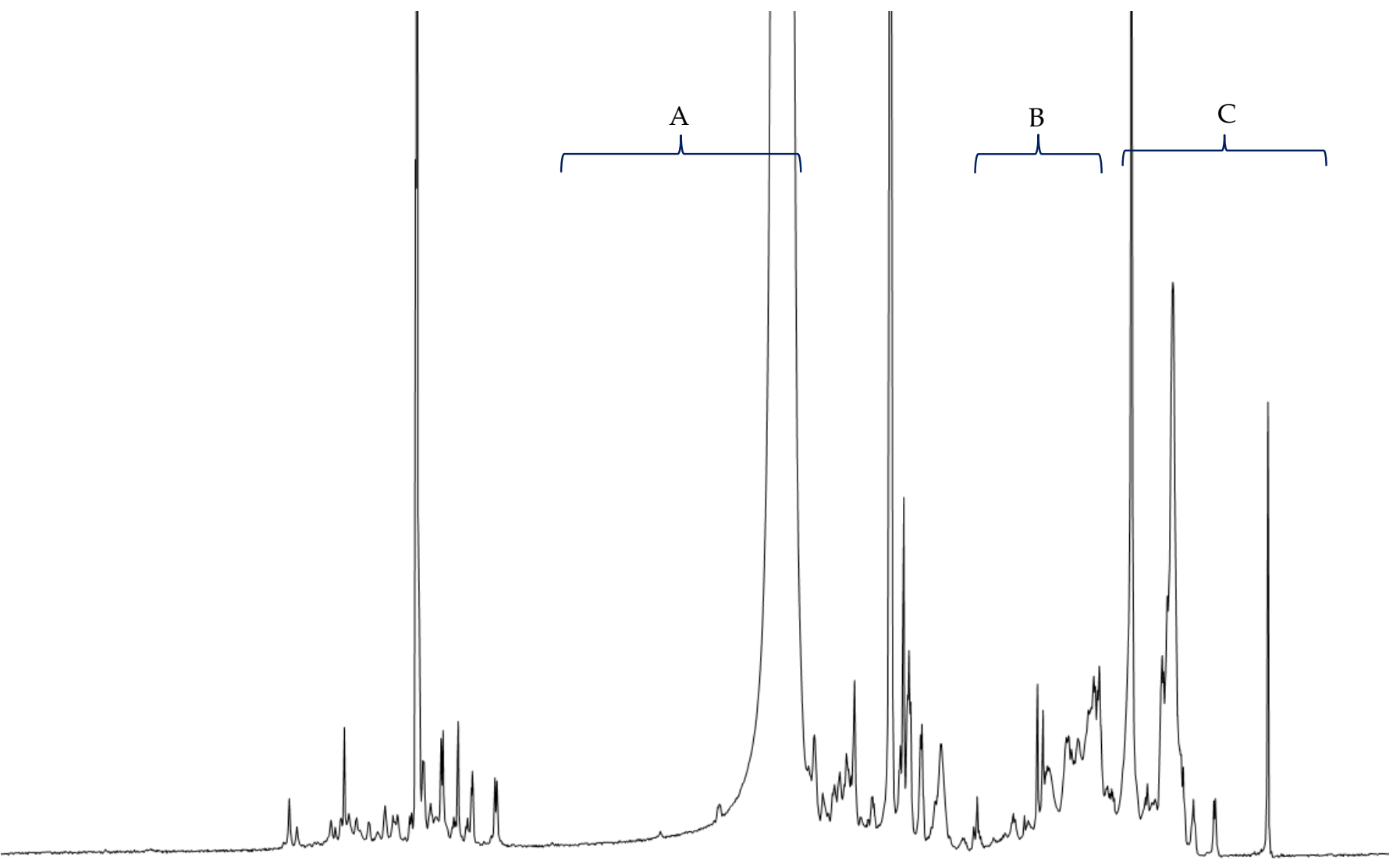

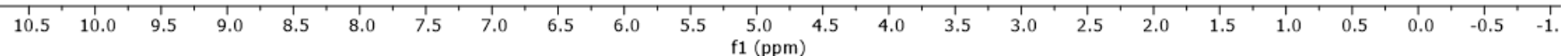

Figure 6. ${ }^{1} \mathrm{H}-\mathrm{NMR}$ spectra $\left(500 \mathrm{MHz}, \mathrm{CD}_{3} \mathrm{OD}\right)$ of Vespa velutina venom obtained by electrical stimulation. 


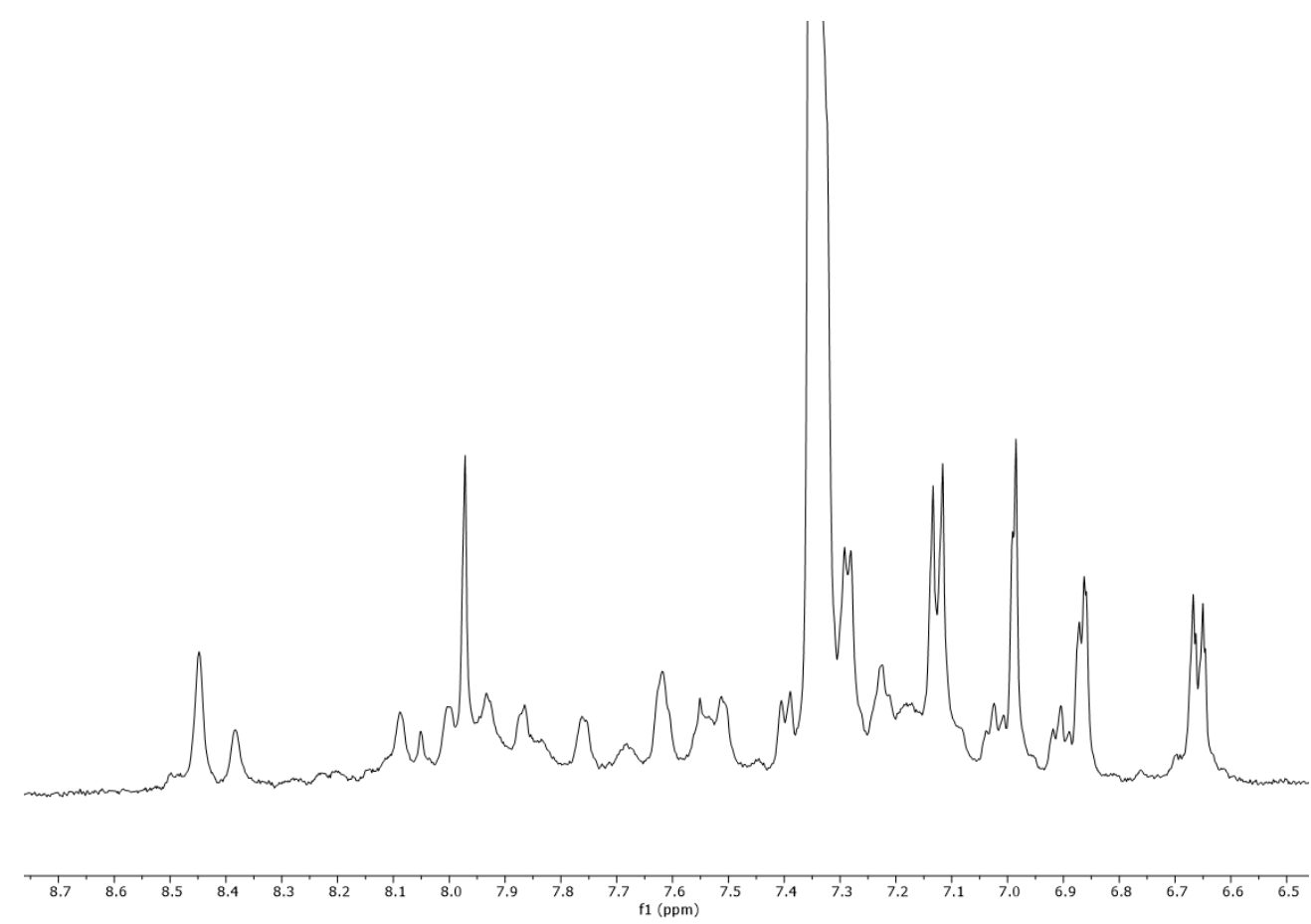

Figure 7. Expanded region A $(\delta=6.5-8.7 \mathrm{ppm})$ of a ${ }^{1} \mathrm{H}-\mathrm{NMR}$ spectra $\left(500 \mathrm{MHz}, \mathrm{CD}_{3} \mathrm{OD}\right)$ of $V e s p a$ velutina venom obtained by electrical stimulation.

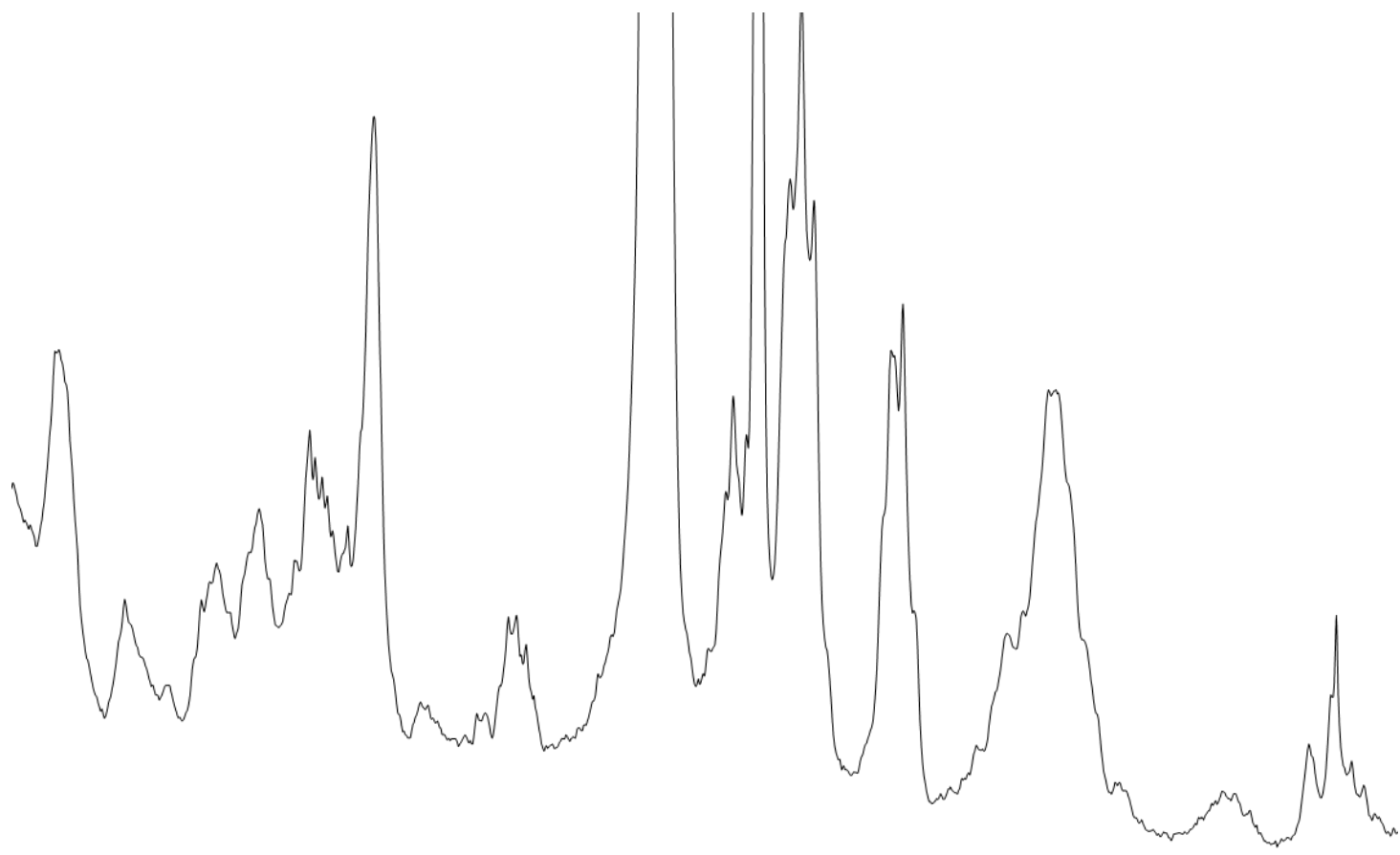
$\begin{array}{lllllllllllllllllllllllllllllllllllll}.95 & 3.90 & 3.85 & 3.80 & 3.75 & 3.70 & 3.65 & 3.60 & 3.55 & 3.50 & 3.45 & 3.40 & 3.35 & 3.30 & 3.25 & 3.20 & 3.15 & 3.10 & 3.05 & 3.00 & 2.95 & 2.90 & 2.85 & 2.80 & 2.75 & 2.70 & 2.65 & 2.60 & 2.55 & 2.50 & 2.45\end{array}$

Figure 8. Expanded region $\mathrm{B}(\delta=2.45-3.95 \mathrm{ppm})$ of a ${ }^{1} \mathrm{H}-\mathrm{NMR}$ spectra $\left(500 \mathrm{MHz}, \mathrm{CD}_{3} \mathrm{OD}\right)$ of $V e s p a$ velutina venom obtained by electrical stimulation. 


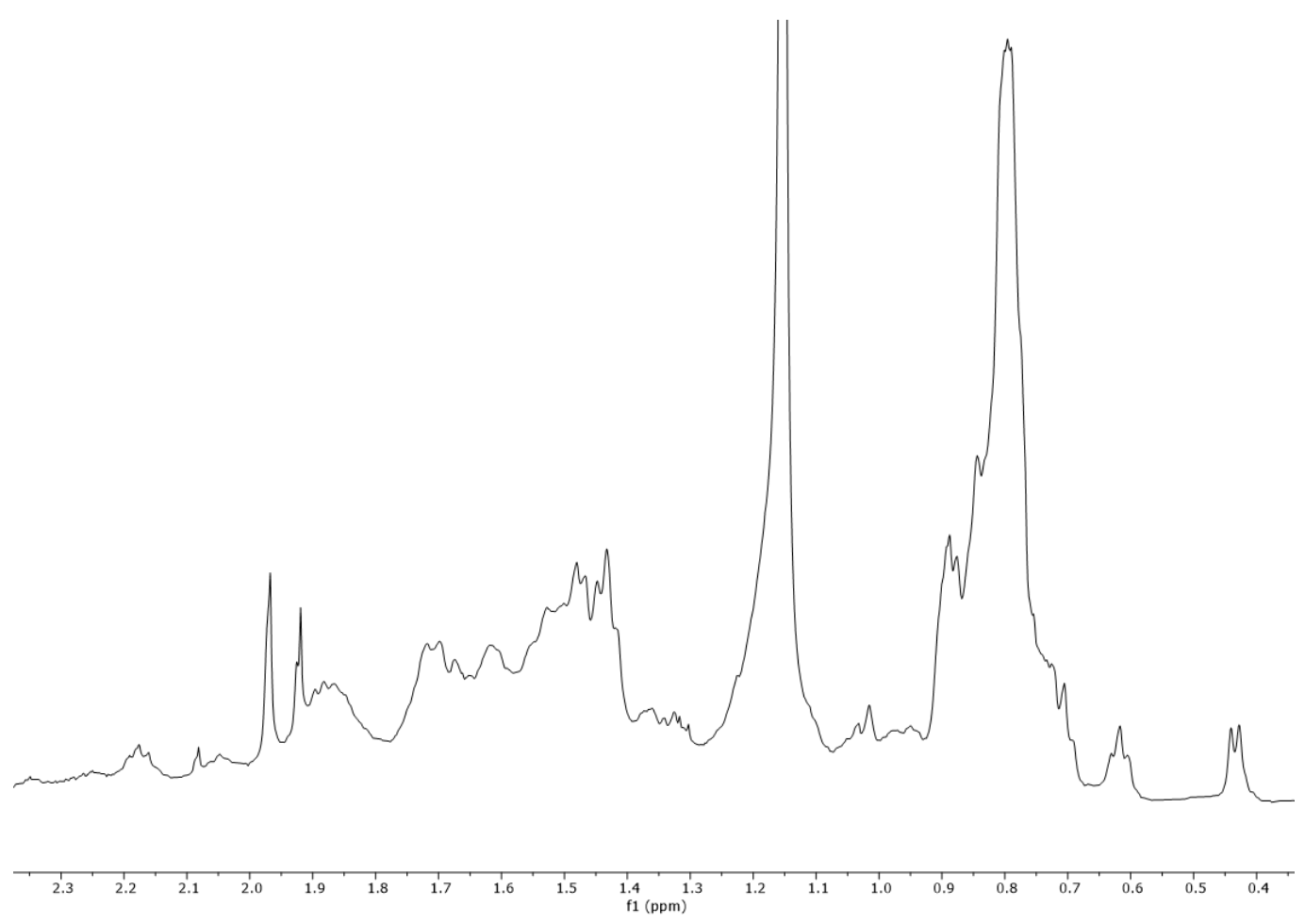

Figure 9. Expanded region $\mathrm{C}(\delta=0.4-2.3 \mathrm{ppm})$ of a ${ }^{1} \mathrm{H}-\mathrm{NMR}$ spectra $\left(500 \mathrm{MHz}, \mathrm{CD}_{3} \mathrm{OD}\right)$ of $V e s p a$ velutina venom obtained by electrical stimulation.

\section{Materials and Methods}

The field study was conducted during September 2017 in one apiary $\left(43^{\circ} 37^{\prime} 15.2^{\prime \prime} \mathrm{N}\right.$ $7^{\circ} 35^{\prime} 26.7^{\prime \prime} \mathrm{W}$ ) located in San Pedro de Viveiro (municipality of Viveiro), in the Western Mariña at the province of Lugo (Galicia, Spain). At an altitude of $177 \mathrm{~m}$ above sea level, the climate in the area is characterized by mildness and rainfall, as corresponds to the oceanic climate. The average annual temperature exceeds $14^{\circ} \mathrm{C}$, while the thermal oscillation is weak $\left(10^{\circ} \mathrm{C}\right)$, as a result of a mild winter and moderate temperatures in summer.

Adult female Vespa velutina specimens were obtained while using an active collecting net method at an apiary. The apiary had a total of (i) six beehives with a frontal protective module, a grid which prevents the entry of the Vespa velutina into the beehive; and (ii) 12 traps situated at the beehives consisted of a $15 \mathrm{~L}$ plastic box (width $=36.5 \mathrm{~cm}$; depth $=$ $28.5 \mathrm{~cm}$; height $=18.5 \mathrm{~cm}$ ) with four holes on the sides of each box. The bait used consisted of blueberry juice, brown beer, and wax obtained from honey bee combs.

\subsection{Materials}

\subsubsection{Protective Equipment}

A full body protective apiary suit, consisting of one-piece pants and jacket, hat, veil, and a pair of long-sleeve beekeeping gloves that was worn by the operators at the apiary when collecting Vespa velutina specimens. For venom removal, at the lab, it is necessary to use protective equipment: glasses, gloves, and mask to avoid contamination and potential direct contact with the skin and mucosas.

\subsubsection{The Vespa Velutina Venom Extraction Chamber}

System set-up for Vespa velutina venom obtention by electric stimulation consists of a modified container where a venom collection device is located (Figure 10), composed of:

(a) A transparent plastic box $(285 \times 160 \times 120 \mathrm{~mm})$ with a lid and hermetically sealed, in which modifications were made for the introduction of the captured insects (1) and to access the on/off switch of the electrical venom collection device with a stick (2). Two holes consisted of a circular, 30-mm diameter at a height of $70 \mathrm{~mm}$ from the base, for the 
introduction tube (1); and a rectangular aperture $(10 \mathrm{~mm} \times 20 \mathrm{~mm})$ to give access to the on/off switch (2). A 100-mm-length plastic tubing, covered with grey adhesive tape, is inserted into hole number 1 of the plastic box with $45 \mathrm{~mm}$ protruding from the box and a screw cap at the end to prevent escape. Hole number two for the on/off switch mechanism is located at the back of the venom collection device, approx. $75-80 \mathrm{~mm}$ from the base of the box.

(b) An electrical venom collection device was supplied by IGK Electronics (Varna, Bulgaria), designed to harvest honey bee venom. The device consists of a solid wooden frame $(250 \times 158 \times 38 \mathrm{~mm})$ having an area 250 by $158 \mathrm{~mm}$ over which 39 wires are stretched at $3 \mathrm{~mm}$ intervals (Figure 10). A removable glass plate $(201 \times 140 \times 4 \mathrm{~mm})$ fits under the wires.

Modified transparent plastic box

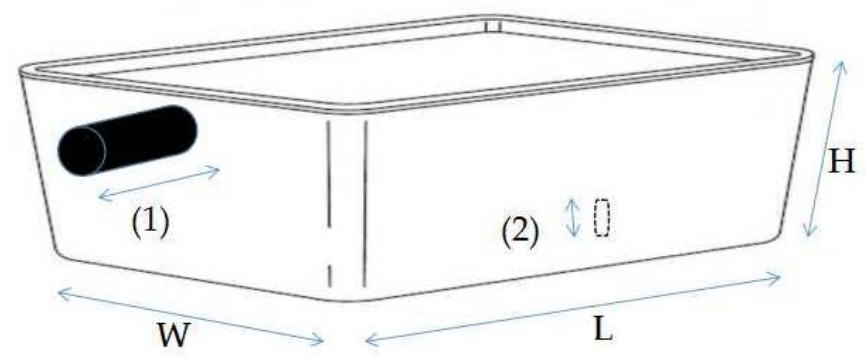

Electrical venom collection device

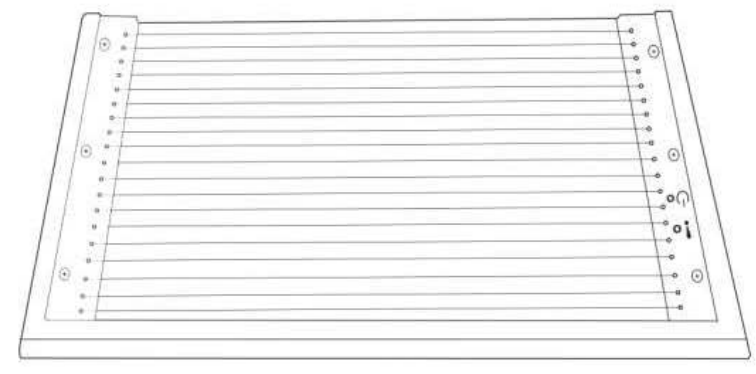

Figure 10. System set-up for Vespa velutina venom obtention chamber by electric stimulation.

\subsection{Collecting Insects and Venom}

3.2.1. Identification of Vespa Velutina Individuals

Insects were identified using their external morphological characteristics. In brief, Vespa velutina averages about $2-3 \mathrm{~cm}$ in length, the head is black with the face and mouthparts orange, and the antennae are brown dorsally and orange ventrally. The thorax is dark brown, almost black. Metasomal terga is brown, with a thin yellow band on the first segment and a thin orange band on the second and third segments; the fourth metasomal segment is orange; metasomal segments five and six are orange-brown. The legs are brown, with yellow tarsi, and the wings are brownish hyaline.

\subsubsection{Catching the Insects}

The collection of Vespa velutina specimens $(n=30)$ hovering in front of the beehives or the traps was performed by horizontally swinging the net quickly across the hornet, to capture the specimen and then follow through swipe to force the insect into the very bottom of the net bag tip. The above is performed with a fast twist of the wrist so that the bottom of the net bag hangs over the rim. If necessary, with the rim of the net in contact with the ground, hold the tip of the bag up with one hand. The Vespa velutina will fly or walk upward into the net at the tip of the bag, which can then be flipped over with the hand to entrap the specimen, keeping a sufficient amount of netting between the hand and insect.

\subsubsection{Transfer the Insects to the Venom Collection Chamber}

The trapped insect in a fold of the tip of the net is then inserted into the Vespa velutina venom extraction chamber. The part of the open net is placed embedded at the entrance of tube number 1 , until we reach the pocket that we are holding with one hand. At this time, the inlet of the tube number one is surrounded with the net, so the insect has free access to the tube entry. Captured insects will crawl voluntarily toward the illuminated side in 
the venom collection box. Once the insect passes through the tube and enters the venom extraction box, which occurs in 3-5 s, the net is removed and the inlet tube is closed with the lid.

\subsubsection{Electric Stimulation}

The glass panels should be sterilized previously with 70-90\% ethyl alcohol. Turn on the venom collector device with the switch On/Off key with a stick through hole number two. The device starts to work and you will see the green LED, flashing slowly: three times, pause, three times. Every minute the electrical device will pause for about $10 \mathrm{~s}$. After about $40 \mathrm{~min}$, the electrical venom collector turns itself off. Once the venom harvesting is complete, the insects $(n=10)$ are removed. Then, the Vespa velutina venom extraction chamber with the fresh Vespa velutina venom on the electrical venom collection device is carefully packed into a container for transportation to the laboratory. Three venom extraction sessions are performed.

\subsubsection{Vespa Velutina Venom Removal and Processing in the Laboratory}

At the lab, the glass plate is pulled out from the electrical venom collection device and inspected visually under UV light. The glass plate is then scraped, with the help of a razor and spatula, and transferred to a vial. Venom scrapings were pooled. The dehydrated venom is then kept in dark bottles and stored in a refrigerator at $-15^{\circ} \mathrm{C}$ pending further analysis (see the Video S1).

\section{3. ${ }^{1} \mathrm{H}-\mathrm{NMR}$ Analysis}

${ }^{1} \mathrm{H}-\mathrm{NMR}$ analyses were performed on a Varian VNMRS-500-WB spectrometer (500 MHz for ${ }^{1} \mathrm{H}$ ) instrument (Agilent Technologies, Palo Alto, CA, USA), equipped with a $5 \mathrm{~mm}$ probe. The sample was dissolved in $500 \mu \mathrm{L}$ of methanol- $\mathrm{d}_{4} \mathrm{CD}_{3} \mathrm{OD}$, (Sigma-Aldrich, Madrid, Spain) shaken in a vortex mixer, and the resulting mixture was placed into 5-mm diameter ultra-precision NMR sample tubes (Norell, Landisville, PA, USA). The temperature of the sample in the probe was $30{ }^{\circ} \mathrm{C}$. The chemical shifts are reported in ppm, using the solvent proton signal as standard. The area of the signals was determined by using the Mestrelab MNova (Mestrelab S.L. Spain, 2016) software, and the integrations were carried out three times to obtain average values. All figures of the ${ }^{1} \mathrm{H}-\mathrm{NMR}$ spectra and the expanded ${ }^{1} \mathrm{H}-\mathrm{NMR}$ spectrum regions were plotted at a fixed value of absolute intensity to be valid for comparative purposes.

Values for the peaks detected are as follows: ${ }^{1} \mathrm{H}-\mathrm{NMR}\left(500 \mathrm{MHz}, \mathrm{CD}_{3} \mathrm{OD}\right) \delta 8.45,8.38$, $8.09,8.05,8.00,7.97,7.93,7.87,7.76,7.75,7.62,7.61,7.55,7.51,7.50,7.29,7.28,7.23,7.14,7.13$, $7.12,7.12,7.02,7.01,6.99,6.98,6.92,6.90,6.87,6.86,6.86,6.67,6.66,6.65,6.65,3.90,3.83,3.74$, $3.73,3.72,3.68,3.62,3.62,3.61,3.60,3.40,3.40,3.38,3.16,3.15,3.14,3.13,3.13,3.10,3.09,3.08$, $3.07,2.99,2.98,2.97,2.80,2.52,2.50,2.49,2.47,2.18,2.16,1.97,1.97,1.93,1.92,1.90,1.88,1.86$, $1.72,1.70,1.67,1.62,1.52,1.48,1.47,1.45,1.43,1.42,1.36,1.34,1.33,1.32,1.30,1.02,0.89,0.89$, $0.88,0.85,0.81,0.80,0.80,0.79,0.77,0.77,0.75,0.73,0.71,0.62,0.44$, and 0.43 .

\section{Conclusions}

We described a straightforward, quick, and inexpensive method for obtaining Vespa velutina venom, based on an electric stimulation protocol, including all sequential steps for sampling, handling, and milking the insect. The materials used are cheap and readily accessible in the market. The Vespa velutina venom extraction chamber can be used in field, since it is totally portable by operators with minimal training. Actually, the Vespa velutina venom extracts obtained by electro stimulation have allowed the initiation of new investigations in the Clinical Immunology Unit of the University Hospital of Santiago de Compostela, which we expect may ultimately promote substantial improvements in the diagnosis, prevention, and medical treatment of severe allergies and anaphylaxis caused by Vespa velutina stings. 
Supplementary Materials: The following supporting information can be downloaded. Video S1: Scraped of the Vespa velutina Lepeletier 1836 venom obtained from a captive nest.

Author Contributions: Conceptualization, X.F.; methodology, X.F., J.A.S. and M.P.V.-T.; formal analysis, C.V.; investigation, C.V.; resources, C.V.; writing-original draft preparation, X.F.; writingreview and editing, X.F., C.V., M.P.V.-T. and J.A.S.; supervision, C.V.; project administration, C.V.; funding acquisition, C.V. All authors have read and agreed to the published version of the manuscript.

Funding: The authors thank the Ministerio de Ciencia y Tecnología (Project MAT2017-86109P) and the Instituto de Salud Carlos III (Fondo de Investigaciones Sanitarias, Spanish Ministry of Health, PI19/01023) (Co-funded by the European Regional Development Fund "A way to make Europe") for the financial support. X.F. thanks Instituto de Salud Carlos III for a research contract (program number: RD16/0017/001).

Institutional Review Board Statement: Asian Hornet, Vespa velutina Lepeletier, 1836 (Hym.: Vespidae) is not a regulated invertebrate. Therefore, no ethical use approval is necessary.

Acknowledgments: We would like to thank to Robert Hogge (former President of the Jersey Beekeepers' Association and founder of Jersey Asian hornet Group) and Sam Day (former Kent Beekeeper's Asian hornet Team Coordinator) for critically reading the manuscript. Thanks also to Jose María Vázquez for the support when sampling at the apiary and to Dani Slizt for obtaining the Vespa velutina nests. Thanks also to José Amoedo Montes and Carmen Cabadas Amoedo for providing the necessary facilities for this work, in San Amaro (Fornelos de Montes, Galicia). Assistance and comments provided by Arturo González-Quintela (Department of Medicine, Complejo Hospitalario Universitario de Santiago) was greatly appreciated.

Conflicts of Interest: The authors declare no conflict of interest.

Sample Availability: Samples of the Vespa velutina venom are available from the authors.

\section{References}

1. Genovesi, P.; Carnevali, L.; Scalera, R. The Impact of Invasive Alien Species on Native Threatened Species in Europe; Technical Report for the European Commission; ISPRA-ISSG: Rome, Italy, January 2015; p. 18.

2. Crystal-Ornelas, R.; Hudgins, E.J.; Cuthbert, R.N.; Haubrock, P.J.; Fantle-Lepczyk, J.; Angulo, E.; Kramer, A.M.; Ballesteros-Mejia, L.; Leroy, B.; Leung, B.; et al. Economic costs of biological invasions within North America. NeoBiota 2021, 67, 485-510. [CrossRef]

3. Zenni, R.D.; Essl, F.; García-Berthou, E.; McDermott, S.M. The economic costs of biological invasions around the world. NeoBiota 2021, 67, 1-9. [CrossRef]

4. Mazza, G.; Tricarico, E.; Genovesi, P.; Gherardi, F. Biological invaders are threats to human health: An overview. Ethol. Ecol. Evol. 2014, 26, 112-129. [CrossRef]

5. Feás Sánchez, X.; Charles, R.J. Notes on the Nest Architecture and Colony Composition in Winter of the Yellow-Legged Asian Hornet, Vespa velutina Lepeletier 1836 (Hym.: Vespidae), in Its Introduced Habitat in Galicia (NW Spain). Insects 2019, 10, 237. [CrossRef] [PubMed]

6. Kim, J.; Choi, M.; Moon, T. Occurrence of Vespa velutina Lepeletier from Korea, and a revised key for Korean Vespa species (Hymenoptera: Vespidae). Entomol. Res. 2006, 36, 112-115. [CrossRef]

7. Haxaire, J.; Bouguet, J.-P.; Tamisier, J.-P. Vespa velutina Lepeletier, 1836, une redoutable nouveauté pour la faune de France (Hymenoptera, Vespidae). Bull. Soc. Entomol. France 2006, 111, 194. [CrossRef]

8. Minoshima, Y.; Yamane, S.K.; Ueno, T. An invasive alien hornet, Vespa velutina nigrithorax du Buysson (Hymenoptera, Vespidae), found in Kitakyushu, Kyushu Island: A first record of the species from mainland Japan. Jpn. J. Syst. Entomol. 2015, $21,259-261$.

9. Takahashi, R.; Sakai, Y.; Yamamura, T.; Kiyoshi, T.; Takahashi, J. Analysis the nest of alien hornet, Vespa velutina, found for the first time in Tsushima Island, Japan. Trans. Nagasaki Biol. Soc. 2015, 76, 49-56.

10. Fedele, E.; Gervasini, E.; Cardoso, A.C.; La Notte, A.; Vallecillo, S.; Tsiamis, K.; Maes, J. Invasive Alien Species impact on Ecosystem Services; Publications Office of the European Union: Luxembourg, 2019. [CrossRef]

11. Baumman, K. Evolution of the Venom System in Aculeate Hymenoptera. Ph.D. Thesis, The University of Queensland, Brisbane, Australia, November 2018.

12. Feás, X. Human Fatalities Caused by Hornet, Wasp and Bee Stings in Spain: Epidemiology at State and Sub-State Level from 1999 to 2018. Biology 2021, 10, 73. [CrossRef] [PubMed]

13. Vidal, C. The Asian wasp Vespa velutina nigrithorax: Entomological and allergological characteristics. Clin. Exp. Allergy 2021, 00, 1-10. [CrossRef] [PubMed]

14. Vidal, C.; Armisén, M.; Monsalve, R.; González-Vidal, T.; Lojo, S.; López-Freire, S.; Méndez, P.; Rodríguez, V.; Romero, L.; Galán, A.; et al. Anaphylaxis to Vespa velutina nigrithorax: Pattern of sensitization for an emerging problem in Western countriesVideo $\mathrm{S}$. J. Investig. Allergol. Clin. Immunol. 2021, 31, 228-235. [CrossRef] 
15. Choi, M.B.; Kim, T.G.; Kwon, O. Recent Trends in Wasp Nest Removal and Hymenoptera Stings in South KoreaVideo S. J. Med. Entomol. 2018, 56, 254-260. [CrossRef]

16. Chugo, S.; Lizaso, M.T.; Alvarez, M.J.; Arroabaren, E.; Lizarza, S.; Tabar, A.I. Vespa velutina nigritorax: A New Causative Agent in AnaphylaxisVideo S. J. Investig. Allergol. Clin. Immunol. 2015, 25, 231-232.

17. Tabar, A.I.; Chugo, S.; Joral, A.; Lizaso, M.T.; Lizarza, S.; Alvarez-Puebla, M.J.; Arroabarren, E.; Vela, C.; Lombardero, M. Vespa Velutina Nigritorax: A new causative agent for anaphylaxis. Clin. Transl. Allergy 2015, 5, 43. [CrossRef]

18. Sahiner, U.M.; Durham, S.R. Hymenoptera Venom Allergy: How Does Venom Immunotherapy Prevent Anaphylaxis From Bee and Wasp Stings? Front. Immunol. 2019, 10, 1959. [CrossRef]

19. Korošec, P.; Jakob, T.; Harb, H.; Heddle, R.; Karabus, S.; de Lima Zollner, R.; Selb, J.; Thong, B.Y.; Zaitoun, F.; Golden, D.; et al. Worldwide perspectives on venom allergy. World Allergy Organ. J. 2019, 12, 100067. [CrossRef]

20. Feás, X.; Vázquez-Tato, M.P.; Seijas, J.A.; Pratima, G.; Nikalje, A.; Fraga-López, F. Extraction and Physicochemical Characterization of Chitin Derived from the Asian Hornet, Vespa velutina Lepeletier 1836 (Hym.: Vespidae). Molecules 2020, 25, 384. [CrossRef] [PubMed]

21. Zlotkin, E.; Gordon, D. Detection, Purification and Receptor Binding Assays of Insect Selective Neurotoxins Derived from Scorpion Venoms. In Neurochemical Techniques in Insect Research; Breer, H., Miller, T.A., Eds.; Springer Series in Experimental Entomology; Springer: Berlin/Heidelberg, Germany, 1985.

22. Dias, N.B.; de Souza, B.M.; Gomes, P.C.; Palma, M.S. Peptide diversity in the venom of the social wasp Polybia paulista (Hymenoptera): A comparison of the intra- and inter-colony compositions. Peptides 2014, 51, 122-130. [CrossRef] [PubMed]

23. Peiren, N.; Vanrobaeys, F.; de Graaf, D.C.; Devreese, B.; Van Beeumen, J.; Jacobs, F.J. The protein composition of honeybee venom reconsidered by a proteomic approach. Biochim. Biophys. Acta 2005, 1752, 1-5. [CrossRef] [PubMed]

24. Sookrung, N.; Wong-din-Dam, S.; Tungtrongchitr, A.; Reamtong, O.; Indrawattana, N.; Sakolvaree, Y.; Visitsunthorn, N.; Manuyakorn, W.; Chaicumpa, W. Proteome and allergenome of Asian wasp, Vespa affinis, venom and IgE reactivity of the venom componentsVideo S. J. Proteome Res. 2014, 13, 1336-1344. [CrossRef]

25. King, T.P.; Alagon, A.C.; Kuan, J.; Sobotka, A.K.; Lichtenstein, L.M. Immunochemical studies of yellowjacket venom proteins Mol. Immunol. 1983, 20, 297-308. [CrossRef]

26. King, T.P.; Kochoumian, L.; Joslyn, A. Wasp venom proteins: Phospholipase A1 and B. Arch. Biochem. Biophys. 1984, $230,1-12$. [CrossRef]

27. King, T.P.; Lu, G.; Gonzalez, M.; Qian, N.; Soldatova, L. Yellow jacket venom allergens, hyaluronidase and phospholipase: Sequence similarity and antigenic cross-reactivity with their hornet and wasp homologs and possible implications for clinical allergyVideo S. J. Allergy Clin. Immunol. 1996, 98, 588-600. [CrossRef]

28. Le, T.N.; Da Silva, D.; Colas, C.; Darrouzet, E.; Baril, P.; Leseurre, L.; Maunit, B. Asian hornet Vespa velutina nigrithorax venom: Evaluation and identification of the bioactive compound responsible for human keratinocyte protection against oxidative stress. Toxicon 2020, 176, 1-9. [CrossRef] [PubMed]

29. Le, T.N.; da Silva, D.; Colas, C.; Darrouzet, E.; Baril, P.; Leseurre, L.; Maunit, B. Development of an LC-MS multivariate nontargeted methodology for differential analysis of the peptide profile of Asian hornet venom (Vespa velutina nigrithorax): Application to the investigation of the impact of collection period variation. Anal. Bioanal. Chem. 2020, 412, 1419-1430. [CrossRef] [PubMed]

30. Monsalve, R.I.; Gutiérrez, R.; Hoof, I.; Lombardero, M. Purification and molecular characterization of phospholipase, antigen 5 and hyaluronidases from the venom of the Asian hornet (Vespa velutina). PLoS ONE 2020, 15, e0225672. [CrossRef]

31. Vidal, C.; Armisén, M.; Monsalve, R.; Gómez-Rial, J.; González-Fernández, T.; Carballada, F.; Lombardero, M.; González-Quintela, A. Vesp v 5 and glycosylated Vesp v 1 are relevant allergens in Vespa velutina nigrithorax anaphylaxis. Clin. Exp. Allergy 2020, 50, 1424-1427. [CrossRef]

32. Li, R.; Zhang, L.; Fang, Y.; Han, B.; Lu, X.; Zhou, T.; Feng, M.; Li, J. Proteome and phosphoproteome analysis of honeybee (Apis mellifera) venom collected from electrical stimulation and manual extraction of the venom gland. BMC Genom. 2013, 14, 766. [CrossRef]

33. Mueller, U.; Reisman, R.; Wypych, J.; Elliott, W.; Steger, R.; Walsh, S.; Arbesman, C. Comparison of vespid venoms collected by electrostimulation and by venom sac extractionVideo S. J. Allergy Clin. Immunol. 1981, 68, 254-261. [CrossRef]

34. Piek, T. Methods for the Collection of Venoms. In Venoms of the Hymenoptera: Biochemical, Pharmacological, and Behavioural Aspects; Piek, T., Ed.; Academic Press: London, UK, 1986; p. 570.

35. Ali, M.A.A.-S.M. Studies on Bee Venom and Its Medical Uses. Int. J. Adv. Res. Technol. 2012, 1, $69-83$.

36. Eskridge, E.M.; Elliott, W.B.; Elliott, A.H.; Eskridge, P.B.; Doerr, J.C.; Schneller, N.; Reisman, R.E. Adaptation of the electrical stimulation procedure for the collection of vespid venoms. Toxicon 1981, 19, 893-897. [CrossRef]

37. Simon, R.P.; Benton, A.W. A Method for Mass Collection of Wasp Venoms. Ann. Entomol. Soc. Am. 1969, 62, 277-278. [CrossRef]

38. de Graaf, D.C.; Brochetto Braga, M.R.; de Abreu, R.M.; Blank, S.; Bridts, C.H.; De Clerck, L.; Devreese, B.; Ebo, D.G.; Ferris, T.J.; Hagendorens, M.M.; et al. Standard methods for Apis mellifera venom researchVideo S. J. Apic. Res. 2020, 60, 1-31. [CrossRef]

39. van Itterbeeck, J.; Feng, Y.; Zhao, M.; Wang, C.; Tan, K.; Saga, T.; Nonaka, K.; Jung, C. Rearing techniques for hornets with emphasis on Vespa velutina (Hymenoptera: Vespidae): A reviewVideo S. J. Asia Pac. Entomol. 2021, 24, 103-107. [CrossRef]

40. Detoni, M.; Féas, X.; Jeanne, R.L.; Loope, K.J.; O’Donnell, S.; Santoro, D.; Sumner, S.; Jandt, J.M. Evolutionary and ecological pressures shaping social wasps collective defenses. Ann. Entomol. Soc. Am. 2020, 113, 407-424. [CrossRef] 
41. Lee, S.H.; Baek, J.H.; Yoon, K.A. Differential Properties of Venom Peptides and Proteins in Solitary vs. Social Hunting Wasps. Toxins 2016, 8, 32. [CrossRef] [PubMed]

42. Abd El-Wahed, A.; Yosri, N.; Sakr, H.H.; Du, M.; Algethami, A.F.M.; Zhao, C.; Abdelazeem, A.H.; Tahir, H.E.; Masry, S.H.D.; AbdelDaim, M.M.; et al. Wasp Venom Biochemical Components and Their Potential in Biological Applications and Nanotechnological Interventions. Toxins 2021, 13, 206. [CrossRef] [PubMed]

43. Vidya, V.; Achar, R.R.; Himathi, M.U.; Akshita, N.; Yogish Somayaji, T.; Kameshwar, V.H.; Byrappa, K.; Ramadas, D. Venom peptides-A comprehensive translational perspective in pain management. Curr. Res. Toxicol. 2021, 9, 329-340.

44. Trim, C.M.; Byrne, L.J.; Trim, S.A. Utilisation of compounds from venoms in drug discovery. Prog. Med. Chem. 2021, 60, 1-66.

45. Pak, S.C. An Introduction to the Toxins Special Issue on "Bee and Wasp Venoms: Biological Characteristics and Therapeutic Application". Toxins 2016, 8, 315. [CrossRef] 